\title{
Perspectivas de mercado para as empresas do APL Pós-Colheita Panambi e Condor na ampliação da capacidade de armazenagem
}

Emerson Juliano Lucca $^{1}$ Dilson Trennepohl ${ }^{2}$

\section{Resumo}

Este trabalho se propõe a apresentar os resultados de um esforço despendido no estudo do mercado de sistemas de armazenagem para grãos e na elaboração de perspectivas para este mercado como cenário para o desenvolvimento do Arranjo Produtivo Local - APL Pós-Colheita Panambi e Condor. Uma atividade econômica somente poderá representar alguma potencialidade para o desenvolvimento de sua região e para as empresas que a realizam se tiver boas perspectivas de mercado. 0 trabalho teve como objeto fazer uma análise das características e das perspectivas de comportamento do mercado para os principais produtos fornecidos pelo APL, condicionada à avaliação do potencial de expansão da produção e das empresas. A metodologia utilizada, a de revisão bibliográfica, proporcionou uma análise reflexiva sobre o assunto, incluindo as características gerais do mercado global e as especificidades que se apresentam para o setor na região de atuação das empresas. Este estudo constatou a necessidade de investimentos ainda mais expressivos em infraestrutura de armazenagem no Brasil, pois, com melhores estruturas e uma melhor capacidade para armazenar a produção, pode ocorrer uma maior competitividade brasileira e um aumento da renda do produtor e demais agentes da cadeia produtiva. Dentro dessa expectativa, as empresas que compõem o APL Pós Colheita de Panambi e Condor teriam plenas condições de ampliar sua capacidade de armazenagem e ocupar uma fatia desse mercado.

Palavras-chave: Desenvolvimento Regional. Arranjo Produtivo Local. Estudo de Mercado.

\footnotetext{
Abstract

This work proposes to present the results of an effort expended in the study of the grain storage systems market and in the elaboration of perspectives for this market as a scenario for the development of the Local Production Arrangement - APL Post-Harvest Panambi and Condor. An economic activity can only represent some potential for

${ }^{1}$ Economista. Doutorando no Programa de Pós-Graduação em Desenvolvimento Regional (Unisc). emerson.lucca@unijui.edu.br

2 Doutor em Desenvolvimento Regional. Professor do Departamento de Ciências Administrativas, Contábeis, Econômicas e da Comunicação da Universidade Regional do Noroeste do Estado do Rio Grande do Sul (Unijuí). dilson@unijui.edu.br
} 
the development of your region and for the companies that carry it out if it has good market prospects. The objective of this study was to analyze the characteristics and perspectives of market behavior for the main products supplied by APL, conditioned to the evaluation of the potential of expansion of production and of companies. The methodology used, that of bibliographic review, provided a reflexive analysis on the subject, including the general characteristics of the global market and the specifics that are presented for the sector in the region where the companies operate. This study verified the need for even more expressive investments in storage infrastructure in Brazil, since with better structures and a better capacity to store production, there could be a greater Brazilian competitiveness and an increase in the income of the producer and other agents of the productive chain. Within this expectation, the companies that make up the APL Post Harvest of Panambi and Condor would have full conditions to expand their storage capacity and occupy a slice of this market.

Keywords: Regional Development. Local Productive Arrangement. Market research.

\section{Introdução}

Uma atividade econômica somente poderá representar alguma potencialidade para o desenvolvimento de sua região e para as empresas que a realizam se tiver boas perspectivas de mercado. É de importância central para este estudo a análise das características e das perspectivas de comportamento do mercado para os principais produtos que compõem o APL Pós-Colheita. A avaliação do potencial de expansão da produção e das empresas inicia-se pelas características gerais do mercado global em que estão inseridas e pelas especificidades que se apresentam para o setor em cada região de atuação das empresas.

Dessa forma, para que o Brasil possa se manter no mercado competitivo de produção de grãos, aumentando as exportações e suprindo a crescente demanda interna, terá que investir não só na produção como também nas etapas pós-colheita, necessárias para que haja o armazenamento de qualidade. Sem esse investimento, o crescimento do setor torna-se inviável, não sendo favorável ao seu desenvolvimento.

Geralmente, as mercadorias necessitam ser armazenadas em momentos específicos durante o processo logístico (BOWERSOX; CLOSS, 2001). Um exemplo é o caso dos grãos, que, na pós-colheita, por insuficiência da rede de armazenagem ou, principalmente, por má conservação de estradas e inadequação do transporte utilizado, há grandes perdas. Dessa forma, salienta-se que o volume de grãos vem aumentando significativamente, e a estrutura de armazenagem não vem acompanhando esse crescimento, ocasionando perdas. Esse processo de perdas ocorre devido à falta de beneficiamento, armazenagem e transporte de grãos (EMBRAPA, 2006).

Sendo assim, a rentabilidade esperada (futura) de uma atividade depende de um número excessivo de variáveis (oferta dos produtores atuais e potenciais; evolução das preferências dos consumidores; emergência de produtos ou serviços substitutos; evolução climática do território-alvo e de seus concorrentes atuais e potenciais, etc., num mundo globalizado), para que se possa fazer um cálculo probabilístico 
qualquer e determinar o grau de confiança que se pode ter no indicador apurado.

Incerteza, porém, não é sinônimo de indeterminação. Até porque o que se faz necessário neste quadro não é calcular com precisão a demanda futura, mas identificar para as distintas atividades abertas à especialização das empresas do APL informações relativas ao mercado global. Dessa forma, levanta-se a seguinte questão: a ampliação da capacidade de armazenagem possibilitará que as empresas do APL Pós-Colheita de Panambi e Condor ocupem uma fatia desse mercado?

Percebendo o crescimento econômico que está ocorrendo no Brasil e tende a persistir nos países da Ásia (China, Índia, etc.), contribuindo para a melhoria da renda e do poder de compra de enormes contingentes populacionais, é um indicador fundamental na projeção do crescimento da demanda mundial. Sendo assim, é possível projetar um crescimento da demanda pelos insumos disponibilizados por este setor.

A importância da demanda é tamanha que a identificação de segmentos com grande potencial de expansão pode levar à sua inclusão dentre as alternativas de especialização produtiva das empresas ou dos territórios, mesmo que ainda não tenham uma grande tradição na atividade, mas representem uma oportunidade clara de expansão. Por isso, estes estudos precisam ser aprofundados e atualizados continuamente pelos agentes do APL, especialmente por sua governança.

O objetivo fundamental desta análise é identificar as tendências para o comportamento da oferta e da demanda por produtos e serviços associados à produção, comercialização e processamento de grãos no território de abrangência das empresas componentes do APL. A partir disso, identificar se a ampliação da capacidade de armazenagem possibilitará que as empresas do APL Pós-Colheita de Panambi e Condor ocupem uma fatia desse mercado. Dessa forma, o artigo está subdividido em quatro seções: na primeira, seguem alguns aspectos da evolução da armazenagem de grãos no Brasil; a segunda aborda as necessidades de ampliação da capacidade armazenada, bem como políticas públicas, certificação e acesso ao mercado. A terceira seção discute a importância do APL para o desenvolvimento regional, e a quarta seção salienta as dificuldades encontradas pelo APL. Finaliza-se com algumas considerações sobre assunto, buscando responder ao problema em questão.

Metodologicamente, o estudo baseou-se na taxionomia proposta por Gil (2000), que classifica a pesquisa quanto aos fins e aos meios. Quanto aos fins, tratase de uma pesquisa descritiva, abordando aspectos da evolução da armazenagem de grãos no Brasil, ampliação da capacidade armazenada bem como políticas públicas, certificações, acesso ao mercado e importância do APL para o desenvolvimento regional. Quanto aos meios, trata-se de uma pesquisa bibliográfica, pois se baseou em material publicado, disponibilizado em livros, artigos e informações do meio eletrônico. O tratamento se deu por meio da análise reflexiva de conteúdo, buscando responder à questão proposta, e pode servir como ponto de partida para futuras análises empíricas ou teorizações sobre o tema.

\section{Evolução da armazenagem de grãos no Brasil}

Em 1990, foi criada a Companhia Nacional de Abastecimento (Conab), órgão 
oficial responsável pelo armazenamento e abastecimento de produtos agropecuários no país. O órgão está vinculado ao Ministério da Agricultura, Pecuária e Abastecimento (MAPA). Entre suas competências, cabe-lhe a execução das políticas públicas referentes ao armazenamento da produção agropecuária, coordenação de políticas oficiais de formação, armazenagem, remoção e escoamento de estoques reguladores e estratégicos de produtos agropecuários. Encarrega-se também da execução das políticas públicas federais, no abastecimento e regulação da oferta de produtos agropecuários no mercado interno, além de outras competências que lhe são atribuídas (CONAB, 2012).

A capacidade estática para armazenagem de grãos cresceu significativamente no Brasil durante as últimas três décadas, passando de 40 milhões de toneladas, em 1980, para mais de 140 milhões de toneladas, em 2010, segundo os dados da Conab. Essa expansão de $250 \%$ no período de 30 anos, o que representa uma taxa anual média de 4,3\%, está intimamente relacionada ao processo de evolução da produção agrícola brasileira e dos instrumentos de política agrícola do governo federal.

Este importante crescimento observado no período precisa ser desdobrado para tornar possível perceber suas especificidades regionais e históricas. Durante a década de 80 , a capacidade estática de armazenagem aumentou $80 \%$, enquanto, na década seguinte, este percentual ficou limitado em 15\% (10 milhões de toneladas, em 10 anos), e, no período de 2000 a 2010, a expansão voltou ao patamar de $70 \%$, com uma taxa média anual de 5,5\%, conforme pode ser visualizado na Figura 1.

Figura 1 - Evolução da produção de grãos e da capacidade de armazenagem - toneladas

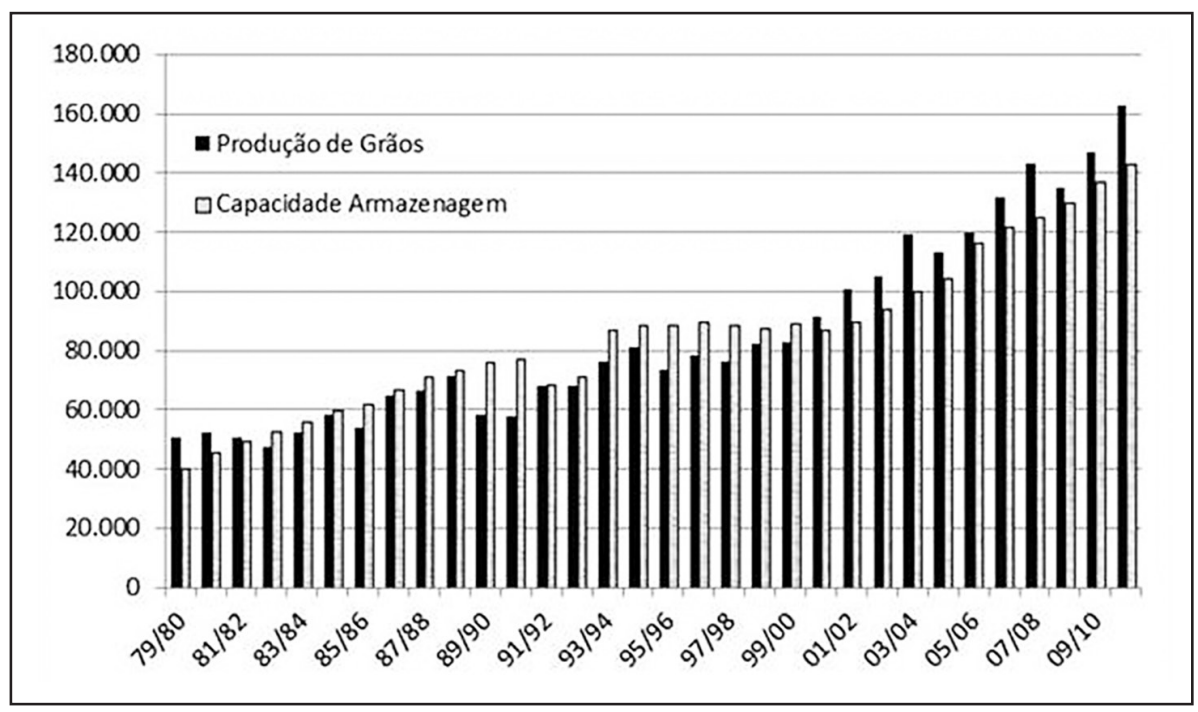

Fonte: Conab (2011). 
Na década de 80, a expansão da capacidade estática foi motivada pela política agrícola do governo federal, que tinha o propósito de garantir o abastecimento interno e regular uma grande quantidade de estoques públicos. A forte intervenção do governo, incentivando os investimentos em armazéns credenciados, contribuiu para gerar uma taxa média anual de $6 \%$ de crescimento no período.

A taxa média de expansão da capacidade estática foi reduzida na década de 90 para 1,5\% ao ano, em consequência das alterações na política agrícola nacional. Nesse período, o Brasil viveu um momento de transformação com o processo de abertura econômica, a introdução do Plano Real, a redução da intervenção do governo por meio da Política de Garantia de Preços Mínimos (PGPM), a redução no montante financeiro de crédito rural.

Na primeira década do novo milênio, após a mudança do regime de política cambial (câmbio fixo para flexível), os produtos brasileiros tornaram-se mais competitivos em relação aos estrangeiros. A introdução de novas tecnologias no sistema de produção nas lavouras proporcionou o aumento de produtividade, e as empresas privadas (tradings, cerealistas e lojas de insumos) aumentaram sua presença na comercialização de produtos agrícolas, com troca de insumos, antecipação de créditos e outras modalidades de financiamentos privados. Com isso, a produção agrícola retomou o crescimento, trazendo consigo a expansão dos armazéns. Nesse período, a taxa média de crescimento da capacidade de armazenagem era de 5,5\% ao ano.

Estudos realizados pela Companhia Nacional de Abastecimento (Conab) apontam que a produção de grãos no Brasil aumentou nos últimos anos, passando de cerca de 83 milhões de toneladas, na safra 1999/2000, para 147 milhões de toneladas, na safra 2011/2012, cujo crescimento pode ser atribuído, entre outros fatores, ao amplo investimento em pesquisa e tecnologia. Nesse sentido, há processos que envolvem os grãos fora da lavoura, ou seja, no pós-colheita, em que os investimentos estagnaram, proporcionando um déficit em armazenagem.

Dessa maneira, nessas três décadas, observou-se um momento com grande intervenção do governo no crescimento dos armazéns do Brasil. O segundo momento trata-se da fase de transição entre a redução da presença do governo no processo de armazenagem e o aumento da iniciativa privada. Por fim, prevaleceu a maior presença da iniciativa privada no processo de armazenagem, assim como no fornecimento de instrumento de comercialização antecipada.

\section{Necessidade da ampliação da capacidade de armazenagem}

O Brasil é um dos países que mais se destaca no cenário mundial da agricultura, devido a sua crescente expansão na produção de grãos. Este destaque é devido aos investimentos realizados em pesquisa e tecnologia na produção agrícola, o que vem contribuindo fortemente para a expansão deste mercado. Esse desempenho da produção, porém, não está sendo acompanhado no que diz respeito aos serviços de comercialização agrícola, principalmente armazenagem e transporte, o que tem desestimulado e enfraquecido a competitividade do produto brasileiro.

Segundo o Instituto de Economia Agrícola (IEA), a tecnologia empregada nas 
atividades agrárias permite produzir não apenas maior quantidade e qualidade por unidade de área como também em épocas e regiões distintas das tradicionalmente conhecidas. Em consequência, os períodos de colheita se estenderam no decorrer do ano com épocas coincidentes, ocorrendo um crescimento substancial da demanda pela modernização da atual infraestrutura de armazenagem e transporte, visando a um eficiente sistema logístico para escoamento das safras (NOGUEIRA JUNIOR; TSUNECHIRO, 2011).

A necessidade da elevação da capacidade de armazenagem revela que o setor tem reagido positivamente ao aumento da produção de grãos. Proporcionalmente ao aumento na formação de novas estruturas de armazenagem localizadas em fazendas, verifica-se o aumento da capacidade estática desse segmento, o que pressupõe que, nessa zona, os investimentos nas instalações de armazenagem tendem a ser maiores. Neste sentido, o armazenamento é considerado uma atividade de apoio fundamental para as etapas de escoamento e comercialização, haja vista que a presença de unidades armazenadoras próximas aos locais de produção, aos mercados consumidores, aos portos e às indústrias de beneficiamento possibilita a racionalização de transporte e a alocação estratégica dos estoques.

A disponibilidade de armazéns no Rio Grande do Sul talvez tenha surpreendido agentes, que, no geral, esperavam que os números fossem menos desfavoráveis, principalmente com a sinalizada preocupação de agentes do setor produtivo do Estado. Em termos agregados, o Estado apresentou superávit de aproximadamente 185 mil toneladas, apontando equilíbrio entre produção agrícola e disponibilidade de armazéns, segundo estudo realizado pelo Centro de Estudos Avançados em Economia Aplicada - Cepea/Esalq-USP (BARROS et al., 2010).

Porém é importante destacar que o mesmo estudo já apresentava um contingente de 21 microrregiões do Estado com déficit em armazenagem, as quais, juntas, necessitariam de armazéns para aproximadamente 4 milhões de toneladas de grãos, caso se objetivasse armazenar toda a produção de um ano/safra. Em contrapartida, outras quatorze microrregiões apresentaram superávit de capacidade, somando mais de 4,1 milhões de toneladas excedentes. Desse total, cerca de 2 milhões de toneladas situam-se em microrregiões próximas ao litoral, longe das unidades produtivas, especialmente das mais necessitadas, que estão no centro-oeste, nordeste e noroeste do Estado. Ajustes nas disponibilidades das regiões mais importantes em produção poderiam diminuir custos e facilitar estratégias de vendas da produção (BARROS et al., 2010).

Ressalta-se que, no estudo apresentado, as microrregiões deficitárias estão localizadas em fronteira agrícola, enquanto as com capacidade adicional ficam em municípios mais tradicionais na produção agrícola do Estado. Mesmo assim, exigem transportes de grãos para grandes distâncias e, muitas vezes, em estradas rurais. A preocupação, entretanto, fica para as microrregiões mais ao norte do Estado, as de fronteira, que apresentam crescimentos mais expressivos da produção agrícola nos últimos anos, exigindo que a comercialização se dê no período de colheita e/ou que o armazenamento ocorra em silos de lona, e não a céu aberto (BARROS et al., 2010). 
Com esse avanço tecnológico e o incentivo de estruturas e armazenamentos, torna-se urgente que os processos de armazenagem contribuam para a manutenção dessa qualidade e, também, para o aumento da velocidade do fluxo de produtos pelo canal logístico. Isso exige a adequação das estruturas existentes, bem como a incorporação de novos armazéns, que, além de reduzir o déficit de algumas regiões, também possam atender às exigências do mercado de segregação de produto.

Em levantamentos apresentados pela Conab (2011), o patamar ideal para a capacidade estática brasileira é $20 \%$ superior à produção do país. Essa margem, em anos anteriores, possibilitou receber e armazenar a safra agrícola em condições adequadas, excetuando-se as áreas tradicionalmente carentes de estruturas armazenadoras. Com as previsões apresentadas em relatórios mais recentes, porém, percebese que a produção está aumentando cada vez mais, demandando uma infraestrutura de armazéns em locais situados em fronteiras e portos fluviais e marítimos.

O governo está se empenhando para que os recursos do Programa de Incentivo à Irrigação e à Armazenagem beneficiem as empresas ligadas ao APL, podendo ser direcionados $25 \%$ para a adequação, recuperação e modernização das estruturas existentes, independentemente da localização dos armazéns. Os 75\% restantes seriam destinados à construção de novos armazéns nas propriedades rurais. O objetivo de continuar a incentivar a construção de armazéns nas propriedades rurais, com recursos públicos, visa a elevar a capacidade estática existente nessa localização. Assim, a Companhia Nacional de Abastecimento (CONAB, 2011) reforça a necessidade da instituição imediata do Sistema Nacional de Certificação de Unidades Armazenadoras, como forma de tornar o setor armazenador mais eficiente, moderno e com credibilidade.

O Plano Nacional de Armazenagem (PNA) de produtos agrícolas do Brasil, que visa corrigir um déficit histórico da capacidade de armazenar produtos, deverá apresentar seus primeiros resultados em breve. Assim sendo, há expectativas de que, com maior capacidade de armazenagem, produtores possam, por exemplo, aproveitar os melhores momentos do mercado para comercializar o seu produto.

Existem pelo menos dez linhas de crédito oficial para financiamento da armazenagem, das quais seis são destinadas a produtores rurais. Segundo estudo apresentado pelo IEA, o governo federal disponibilizou R\$1 bilhão para a construção, adequação e manutenção de armazéns e silos. O propósito é ampliar de $15 \%$ para $30 \%$ a capacidade de armazenagem nas propriedades em alguns anos. Dessa forma, o crescimento da produção, nos próximos dez anos, exigiria capacidade para mais 53,8 milhões de toneladas. Assim, se nenhuma unidade de armazenagem fosse construída nos próximos anos, em 2019/20, o déficit de armazenagem chegaria a 74,5 milhões de toneladas (NOGUEIRA JUNIOR; TSUNECHIRO, 2011).

Para que se estabeleça o equilíbrio entre a capacidade de armazenagem e a produção esperada para os próximos dez anos, adicionados os déficits atuais, a necessidade de investimentos é expressiva. Para equilibrar armazenagem e produção, em 2008, os investimentos chegaram a R\$ 4,9 bilhões, aproximadamente; em 
2019/20, chegariam a $\mathrm{R} \$ 17$ bilhões. Dessa forma, bons programas de financiamento ao setor serão exigidos.

Mesmo diante de um cenário que aponta para a necessidade de expansão da capacidade de armazenamento, por que os investimentos ainda não deslancharam no Brasil? Talvez porque os produtores considerem muito elevado o montante desses investimentos, não vislumbrando retornos rápidos. Além disso, os recursos financeiros para financiamentos (créditos) não são fáceis de obter e também podem não ser suficientes para atender à demanda. Vale lembrar que boa parte dos médios e grandes produtores, de quem se esperaria investimento nesta área, possuem dívidas e podem, consequentemente, não ter acesso aos programas de crédito governamentais. É importante destacar que as unidades armazenadoras, nas propriedades rurais brasileiras, ainda são inferiores às observadas em outros países. Enquanto no Brasil a capacidade de armazenamento nas propriedades situa-se em torno de $20 \%$, observa-se participação de $40 \%$ a $80 \%$ na Argentina, Estados Unidos e França (CONAB, 2005).

Para o setor de armazenagem, alguns outros pontos precisam ser focos de atenção. Dentre eles, o aumento de empresas especializadas no ramo metalúrgico. Provavelmente haverá necessidade de adequação dos sistemas de armazenagem, com vistas a diminuir os custos dessa segregação. Se o potencial de crescimento das culturas tradicionais já é expressivo para os próximos anos, não se pode deixar de citar as boas perspectivas para aumento da produção de outros grãos.

Outro ponto que pode ser foco de análises refere-se ao impacto que mudanças climáticas poderão causar sobre a produção agrícola brasileira. Para pesquisadores, alguns cultivos podem se deslocar entre regiões, alterando o mapeamento atual. Dessa forma, a intensidade do deslocamento poderá impactar, inclusive, os investimentos em armazéns, assim como favorecer a inatividade de algumas unidades até então existentes. De qualquer forma, fica clara a necessidade de investimentos ainda mais expressivos em infraestrutura de armazenagem no Brasil.

Devido ao aumento da produção e maior produtividade, a melhora da estrutura e da capacidade de armazenagem pode beneficiar a competitividade brasileira e a renda do produtor. Os investimentos, entretanto, também não podem ser feitos sem recursos disponíveis para a manutenção dos estoques, o que abre um novo ponto a ser melhorado pelos formuladores de políticas.

O Plano Nacional de Armazenagem do Brasil, que visa corrigir um déficit histórico da capacidade de armazenar produtos, deverá apresentar seus primeiros resultados no ano de 2013. A expectativa das empresas ligadas ao APL é que se viabilizem novos incentivos às empresas e ao produtor para o custeio de novos armazéns, proporcionando aos produtores uma maior capacidade de armazenamento para que consigam aproveitar os melhores momentos do mercado para comercializar o seu produto.

Segundo pesquisa feita pelo Instituto de Economia Agrícola (IEA), em 2011, o agronegócio brasileiro merece uma atenção redobrada em relação à capacidade estática de armazenamento de grãos, para que se tenham garantias no abastecimento interno e no mercado externo, além de incentivos para estruturas padronizadas, tanto nos aspectos de qualidade como de localização geográfica. Devido à migração 
de lavouras, muitas regiões carecem de uma rede de armazenagem, enquanto outras até apresentam superávits (NOGUEIRA JUNIOR; TSUNECHIRO, 2011).

Apesar dos déficits em armazenagem serem expressivos, um fator que deve ser considerado é a rotação de estoques. As análises efetuadas no Centro de Estudos Avançados em Economia Aplicada - Cepea/Esalq-USP -, consideraram a possibilidade de armazenar toda a produção de um ano sem nenhuma comercialização. Sabese, contudo, que isso geralmente não acontece. Conforme a colheita avança, a comercialização é intensificada, e o ritmo acelera, ou diminui de acordo com os níveis de preços. Se considerados atrativos, produtores procuram negociar lotes maiores (BARROS et al., 2010). No mesmo estudo, analisaram-se os dados sobre produção e capacidade estática total de armazenagem no Brasil. Foi observado que, até final da década de 90, a produção de grãos era inferior à capacidade de armazenagem no país. Nos anos seguintes, a abertura de novas áreas agrícolas, ajustes em sistema de produção, como a intensificação da cultura de segunda safra, especialmente no Centro-Oeste brasileiro, fizeram com que a produção de grãos desse um salto expressivo. O crescimento da produção de soja e milho foi o destaque. Os investimentos em infraestrutura, contudo, não seguiram os mesmos passos e nem o crescimento observado no setor agrícola (BARROS et al., 2010).

Com base em produções agrícolas anteriores, o Cepea/Esalq-USP destaca que o déficit brasileiro de armazenagem ficou em aproximadamente 16 milhões de toneladas. É importante, porém, analisar a situação considerando os armazéns inativos, o que, na maioria das vezes deve-se à condição inadequada das unidades, não permitindo seu uso. Dados do IBGE indicam que, em 2009, o Brasil possuía 5,8 milhões de toneladas em armazéns inativos. Com isso, o déficit nacional de armazenagem seria de 21,7 milhões de toneladas, caso se objetivasse armazenar toda a produção do ano agrícola de 2008 (BARROS et al., 2010).

Apesar dos números já serem expressivos em termos agregados no Brasil, algumas considerações podem ser tomadas ao analisar a situação de cada Estado individualmente. O Estado do Mato Grosso, por exemplo, que possui a maior capacidade instalada de armazéns no Brasil, possui um déficit de aproximadamente 1,6 milhão de toneladas, consideradas as informações de armazéns inativos, segundo o Instituto Brasileiro de Geografia e Estatística (IBGE). Já o Paraná, que possui a segunda maior capacidade instalada do país, apresentou um déficit superior a 7 milhões de toneladas. Os Estados de Rio Grande do Sul, Goiás e São Paulo, que apresentam as maiores capacidades instaladas na sequência, sinalizaram déficits pequenos, quando não superávits (BARROS et al., 2010).

Em diversas regiões do Brasil, como no Norte e no Centro-Oeste, conforme estudo realizado pela Conab, existe um grande número de unidades armazenadoras com impedimento. Embora aparentemente não haja veto, a situação de funcionamento dessas unidades não se apresenta em plena conformidade para a prestação de serviços e diminuição das perdas pós-colheita. Neste sentido, para regularizar as situações, os locais de armazenagens devem ter a certificação de unidades armazenadoras (NOGUEIRA JUNIOR; TSUNECHIRO, 2011). 
A partir do Decreto no 3.385, de 3 de julho de 2001, a Conab passou a recadastrar as unidades armazenadoras no país. O decreto obrigou as empresas jurídicas que prestam serviços a terceiros a prestar informações relativas ao Cadastro Nacional de Unidades Armazenadoras. A partir de 2006, a Conab institucionalizou que produtos agrícolas beneficiados por qualquer instrumento de comercialização do governo federal devem ser depositados em unidades cadastradas em seu sistema (DECKERS, 2006).

O Sistema Nacional de Certificação de Unidades Armazenadoras (SNCUA) tem por objetivo estabelecer um padrão de qualidade na prestação de serviços de armazenagem em cumprimento às exigências cada vez mais rigorosas por parte dos consumidores. Essa certificação proporciona um indicativo que os produtores demandem uma maior quantidade e qualidade de equipamentos pós-colheita.

O Sistema de Certificação visa adequar as instalações e melhorar a gestão das unidades, com benefícios na melhoria da qualidade e na redução das perdas dos produtos armazenados. Deverão ocorrer benefícios para as cadeias de produção de grãos nos curto e médio prazos (NOGUEIRA JUNIOR; TSUNECHIRO, 2011, p. 4).

Segundo estudo realizado pela Conab (2005), quando se analisou a questão de logística, a capacidade de expansão da agricultura brasileira estava próxima do seu limite, pela falta de infraestrutura para escoar a produção e pela incapacidade de armazenar de forma adequada a safra nacional. Além de todas as dificuldades com a infraestrutura de transporte e armazenagem existente, adicione-se que essa precariedade é responsável por uma perda significativa de alimentos, representando uma evasão de recursos suficientes para modificar o perfil desses segmentos.

Para produtores com pequenas áreas de produtividade, a contratação dos financiamentos é difícil por exigir um volume de produção compensatório. Para pesquisadores da IEA, a baixa capacidade de armazenamento nas propriedades rurais não chega a 20\%, demonstrando uma situação desfavorável do Brasil perante os grandes produtores mundiais de grãos, que têm no campo a maior parcela das unidades para guardar seus produtos. Analisando as condições nas quais os produtores se encontram, a sua comercialização é quase sempre em mercado futuro ou épocas pós-colheita, ocasionando preços baixos, além de causar problemas de logística, com congestionamentos nas redes de armazenagem intermediária e terminal (NOGUEIRA JUNIOR; TSUNECHIRO, 2011).

Parte representativa dos agricultores continua com dívidas pendentes, e a elevada soma de recursos exigida para a construção de silos dificulta a ampliação e a modernização do setor. Mesmo assim, fica o questionamento sobre as ações que são tomadas por agentes diante de números tão expressivos.

Neste sentido, diagnosticar os problemas de armazenagem no Brasil requer, em primeira instância, um entendimento da relação e da natureza do déficit existente e a forma de equacionamento do problema para propiciar uma solução adequada. A correlação da capacidade estática de armazenagem com a produção agrícola é um 
simples indicador quantitativo que pode não expressar a real situação, principalmente em âmbito regional.

\subsection{Capacidade de acesso e competitividade do APL no mercado}

As perspectivas de expansão do mercado são importantes para quem tem condições de acessá-lo e de dele se sustentar, mas não são suficientes para os produtores marginais, que tendem a ser expulsos por concorrentes mais eficientes. Para ter acesso qualificado aos grandes mercados, especialmente a suas faixas mais rentáveis, é importante possuir uma capacidade produtiva compatível com os níveis de qualidade, produtividade e custos internacionais, bem como dispor de uma infraestrutura adequada e de um sistema de serviços que não apenas viabilize a comercialização eficiente como, na medida do possível, permita a apropriação do valor agregado por agentes do próprio arranjo. Cada produto possui seus requisitos específicos de produção, transporte, instalação, padronização, fiscalização, dentre outros, que poderão implicar diferenciais de competitividade regional ou empresarial.

Sendo assim, Smith (1982) aborda que a divisão do trabalho é limitada pelo tamanho/extensão do mercado, tamanho econômico da região determinada ou também o de sua população, que, de certo modo, impede a especialização/divisão do trabalho (isso ocorre principalmente no interior, pelo mercado restrito - dificuldades de acesso que culminam em maiores custos de transportes). Smith (1982) ainda relata que regiões em rotas comerciais tendem a aprimorar a divisão do trabalho pelo fácil acesso aos mercados.

A análise da trajetória histórica de participação do APL, nos mercados nacional e mundial, em cada atividade, permite identificar as características determinantes de sua capacidade competitiva. Na evolução dos dados estatísticos, é possível perceber a importância e o peso relativo que representam os diversos aspectos da competitividade em cada circunstância de mercado. Os avanços ou recuos nas fatias de mercado ocupadas pela região estão associados aos efeitos das políticas públicas e aos diferenciais de qualidade, produtividade e custos de cada empresa e da atividade específica que realiza.

A capacidade produtiva de uma região está relacionada, em primeiro lugar, às condições naturais de produção. Nesse sentido, é de fundamental importância identificar as características necessárias para que a produção de cada atividade ocorra adequadamente e a relação de tais necessidades com as características existentes na região. Foi o caso das vantagens competitivas apresentadas pela região em termos de solo, topografia, vegetação, clima e estrutura fundiária que viabilizaram o desenvolvimento da produção de trigo e de soja nos anos de 50 a 80.

Em segundo lugar, a capacidade competitiva de uma região está relacionada com as condições criadas pelos agentes privados e pelos órgãos de execução das políticas públicas. Tais condições dizem respeito ao desenvolvimento da pesquisa para geração de inovações tecnológicas, insumos mais baratos, ou mais eficazes; qualificação da infraestrutura de energia, transporte; comunicação necessária para o desenvolvimento dos serviços de comercialização da produção ou de acesso aos forne- 
cedores de máquinas, equipamentos e insumos necessários à produção; existência de sistemas de crédito rural e de assistência técnica e extensão rural que permitam o fomento das inovações tecnológicas.

Enfim, o envolvimento nas grandes economias de mercado tem sido o caminho clássico pelo qual as economias regionais se expandiram. Isso resultou em especialização, economias externas, desenvolvimento das indústrias locais e aumento da desintegração vertical como resultado da expansão do mercado - sucesso diferencial das economias regionais no mundo contemporâneo (NORTH, 1959).

Para North (1959), um comércio de exportação agrícola bem sucedido pode e realmente tem induzido à urbanização, aos aperfeiçoamentos do mercado de fatores e a uma alocação mais eficiente dos recursos para investimento. Desse modo, o desenvolvimento regional gira em torno da capacidade de uma região de se integrar nos grandes mercados mundiais, através das exportações e da resultante estrutura da economia regional, que influenciará sua capacidade para alcançar o crescimento sustentado e um padrão diversificado de atividade econômica. As condições criadas ou produzidas pelos agentes econômicos, com o apoio governamental, normalmente estão relacionadas às condições naturais existentes e contribuem para eliminar, superar ou amenizar os efeitos de obstáculos à competitividade e/ou para melhorar o aproveitamento de potencialidades existentes.

\section{A Importância do APL Pós-Colheita no Desenvolvimento Regional}

A capacidade competitiva estrutural do APL precisa ser percebida na evolução da situação efetiva de mercado, e não apenas em termos abstratos ou hipotéticos. Os diferenciais de produtividade, qualidade e custos (de produção e de transferência) podem sofrer alterações significativas ao longo do tempo, e a análise dessa evolução pode apontar elementos de determinação da capacidade competitiva regional.

O APL Pós-Colheita encontra-se com um mercado de trabalho aquecido, e ainda há o enfrentamento de algumas dificuldades, tais como falta de mão de obra especializada, devido à evasão para outros municípios e Estados, bem como a sua elevada rotatividade entre as empresas. Estes problemas devem-se, em especial, às crises do setor, provocadas por estiagens recorrentes e alterações nos preços agrícolas, como ocorreu entre 2004 e 2006, caracterizadas pela queda de $73 \%$ na fabricação de silos e secadores metálicos, máquinas de limpeza e transportadores de grãos.

Atualmente, em relação à infraestrutura do aglomerado, destacam-se alguns pontos positivos, dentre eles, equipamentos de produção modernos, acesso ao crédito, para a aquisição de equipamentos de produção, e proximidade de empresas montadoras, ou seja, fabricantes de equipamentos. Dessa forma, Marshall (1982) acrescenta como ponto positivo que, tanto para os clientes quanto vendedores, a visita às firmas que se encontram concentradas em um determinado espaço facilita o acesso, permitindo sua formação. Sendo assim, as firmas que fazem parte de uma aglomeração são as primeiras a conhecer e incorporar as novidades, as inovações, sejam elas em matérias-primas, em maquinário, em processos ou em produtos finais, desde que essas inovações sejam comercializáveis e contem com representantes. 
À medida que a aglomeração cresce, ela passa a atrair para o seu entorno os produtores das principais matérias-primas e insumos utilizados pelas empresas que a compõem, o que induz mais firmas compradoras a se instalarem perto desses fornecedores e vice-versa, num círculo virtuoso sem fim pré-estabelecido. Entre os pontos negativos, porém, ainda estão a falta de capital de giro, a necessidade de ampliação do distrito industrial, a distância dos fornecedores da matéria prima, de um aeroporto regional e do mercado comprador (BRASIL, 2009).

Nos estudos realizados por Paiva (1998), é muito difícil direcionar a dinâmica de um arranjo produtivo, porquanto este carece de estruturas de governança. $\mathrm{Na}$ verdade, quando um APL constitui estruturas de governança, ele deixa de ser um mero arranjo e passa a ser um sistema produtivo local (SPL). Esta é outra transição, tão ou mais complexa que a transição de aglomeração para arranjo produtivo. E também ela tem a sua história de desenvolvimento. Senão vejamos.

A diversidade e complexidade dos arranjos produtivos e os conflitos internos (entre fornecedores e clientes, entre trabalhadores e empresários, entre industriais e agentes comerciais, etc.) que Ihes são inerentes estimulam a criação de instâncias de congraçamento e organização dos agentes produtivos. E formam-se círculos de empresários, círculos de operários e de trabalhadores do conhecimento.

Em um arranjo produtivo consolidado:

[...] os segredos da profissão deixam de ser segredos, e, por assim dizer, ficam soltos no ar, de modo que as crianças absorvem inconscientemente grande número deles. Aprecia-se devidamente um trabalho bem feito, discutem-se imediatamente os méritos de inventos e melhorias na maquinaria, nos métodos e na organização geral da empresa. Se um lança uma ideia nova, ela é imediatamente adotada por outros, que a combinam com sugestões próprias e, assim, essa ideia se torna uma fonte de outras ideias novas (MARSHALL, 1982, p. 234).

Paralelamente aos diagnósticos complementares, é importante levantar informações sobre o mercado. Percebe-se que a desinformação de mercado determina uma grande concentração das empresas no mesmo segmento, acirrando a concorrência predatória e diminuindo o ambiente propício à cooperação. Nesse sentido, a pesquisa de mercado é importante para mostrar a existência de outros segmentos, além daquele normalmente explorado pelas empresas do polo, quantificando o tamanho total do mercado e de seus segmentos. Essas informações permitirão às empresas escolherem a estratégia de atuação e definirem os tipos de competências a serem desenvolvidas em diferentes níveis. Assim, novas oportunidades reduzem a concentração nos mesmos clientes e canais, diminuindo a concorrência direta entre as empresas do APL, auxiliando-as a romperem o padrão de concorrência predatória e gerando um ambiente mais propício à cooperação (BRASIL, 2011).

Nesse sentido, os segmentos de mercado, especificadamente no APL PósColheita de Panambi e Condor, são os agrícola (equipamentos agrícolas); leiteiro (equipamentos de ordenha e acondicionamento de leite); automação industrial; painéis e quadros de comandos elétricos e automotivos (peças e componentes). Estes conferem maior diversificação de produtos ofertados, dentre eles silos e secadores 
metálicos; máquinas de limpeza; transportadores de cereais; termometrias; pivôs de irrigação; ordenhadeiras e demais estruturas, peças, componentes e conjuntos metálicos. Tais produtos possuem um perfil de distribuição predominantemente ao consumidor final (70\%), seguido do consumidor industrial (22\%), enquanto que as vendas diretamente ao mercado externo significam $8 \%$, ou seja, $92 \%$ das vendas são para o mercado interno. Segundo o Plano de Desenvolvimento do Arranjo Produtivo Local Metalomecânico Pós-Colheita, do Ministério do Desenvolvimento, Indústria e Comércio Exterior (BRASIL, 2009), vendas para o mercado externo acontecem para os seguintes países: Emirados Árabes, Turquia, Uruguai, Argentina, Paraguai, Venezuela, Colômbia, Bolívia e África do Sul.

De acordo com o Manual de Apoio aos Arranjos Produtivos Locais (BRASIL, 2008), um fator apto a garantir a sustentabilidade da competitividade do APL exige apoio externo coordenado: as interações das empresas empreendedoras localizadas no aglomerado com o mercado nacional e internacional. A partir da identificação dos agentes de tais interações, a velocidade com que as mudanças acontecem e a forma como os aglomerados, enquanto comunidade de firmas, respondem a essas mudanças, otimizando seu aproveitamento, devem ser promovidas.

Isso porque, cada vez mais, os países e as empresas que apresentam maior competitividade não são aqueles com acesso aos insumos de custo mais baixo, mas os que empregam a tecnologia e os métodos mais avançados na sua utilização. $A$ estrutura e a evolução dos setores e a maneira como as empresas conquistam e sustentam a vantagem competitiva nas respectivas áreas de atuação passaram a ser o cerne da competição.

No Manual, explica-se que a vantagem competitiva resulta de uma combinação efetiva de circunstâncias nacionais mais estratégia empresarial. As condições num país podem criar um cenário no qual as empresas podem alcançar vantagem competitiva internacional, mas compete à empresa aproveitar-se dessa oportunidade. Da adoção de uma posição estratégica claramente definida e focada na mudança, é que vem a vantagem competitiva.

Em termos de competição em produto, processo, materiais e organização, os aglomerados produtivos geralmente se posicionam de duas formas: em um lado estão grupos de firmas dominados por firmas líderes, externas ao $\mathrm{APL}$, que controlam uma das fases finais na cadeia de produção e ditam o design do produto. E ao longo do espectro, um mix de subcontratadores e firmas com design, processos, organização e seleção de materiais independentes. Quanto maior for a capacidade de definição independente, maior é o poder de um APL para coletivamente formatar, em vez de reagir a mercados, elevando, assim, as margens de lucro (BRASIL, 2008, p. 16-17).

Essa perspectiva, tempo, ou seja, viabilidade de longo prazo, mostra-se essencial. As firmas que não constroem internamente capacidade para antecipar mudanças e aproveitar as oportunidades perderão espaço para os competidores que o fazem, não importa onde eficientemente alocam recursos dentro das condições preexistentes. Assim, no centro da nova competição, está a firma empreendedora, definida como uma empresa construída para perseguir melhoria contínua em métodos, produtos e processos, colocando ênfase nos diferentes modos de organização, 
avançando competitivamente pelo design superior do produto e olhando os mercados do mundo todo (BEST, 1990).

\section{Dificuldades encontradas pelo APL}

A gestão para capacitação dos APLs, nesse contexto, tem por objetivo promover o aumento da competitividade por meio de articulações entre empresas e instituições locais em ações conjuntas voltadas para o desenvolvimento da produção, para a cooperação e o aprendizado em âmbito local.

Mais especificadamente, em relação ao APL Metalmecânico Pós-Colheita de Panambi - Condor (RS), no atendimento ao mercado nacional e ao mercado externo, as empresas do APL têm enfrentado dificuldades relacionadas ao acesso ao consumidor final; acesso aos canais de comercialização e distribuição de seus produtos; atendimento das especificações solicitadas pelo importador; promoção dos produtos e fixação de marca; burocracia alfandegária e tributária; embalagem e armazenagem; custos portuários, de transporte interno e de fretes internacionais.

No entanto, com as políticas públicas de incentivo que o governo está propondo, o APL Pós-Colheita tende a sobrepor-se, fortificando-se. Destaca-se o Plano Nacional de Armazenagem (PNA), visto como uma forte ferramenta que tende a possibilitar novos formatos de incentivo e acesso ao crédito, a fim de corrigir um déficit histórico da capacidade de armazenar produtos.

Figura 2 - Participação Setorial na Armazenagem

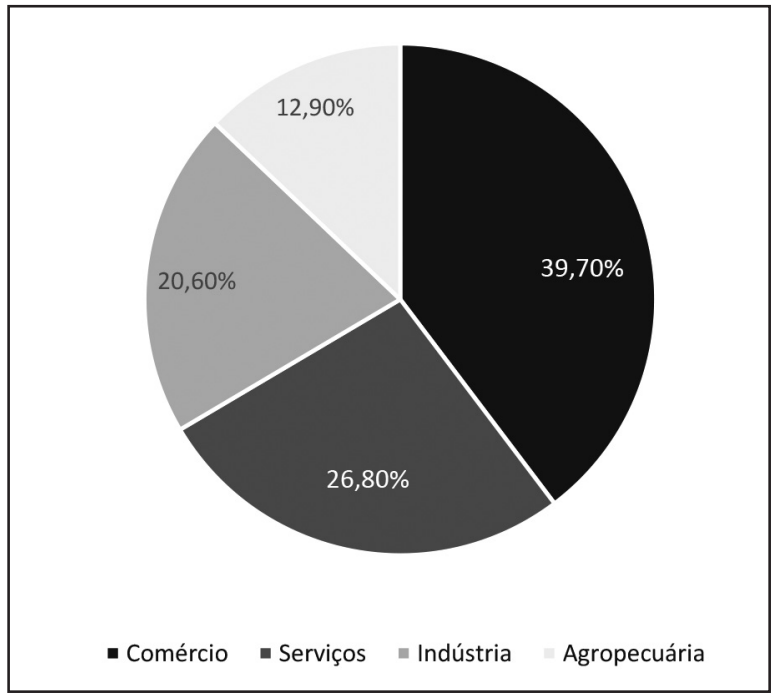

Fonte: Conab (2011). 


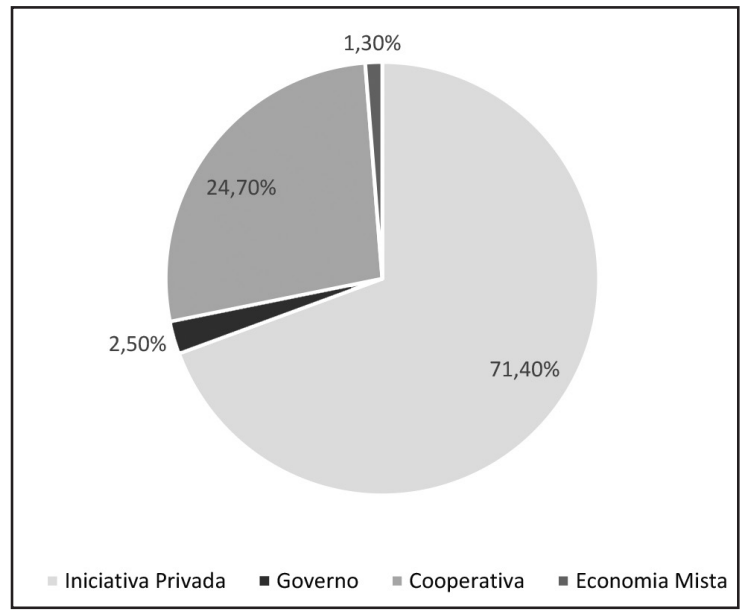

Fonte: Conab (2011).

Para avaliar o potencial da demanda pelos distintos componentes dos sistemas de armazenagem, é importante observar como está distribuída atualmente a capacidade estática de armazenagem no Brasil. De acordo com os dados da Conab, apresentados nas Figuras 2 e 3, a participação do governo e das empresas de economia mista é pouco representativa, enquanto as cooperativas respondem por $24,7 \%$, e a iniciativa privada por $71,4 \%$ da capacidade estática total. Já numa perspectiva setorial, a produção agropecuária possui apenas 12,9\% da capacidade estática, enquanto que a indústria responde por $20,6 \%$; o comércio, por $26,8 \%$, e os prestadores de serviços de armazenagem, por $39,7 \%$ do total.

A continuar essa perspectiva, os grandes demandantes por sistemas de armazenagem serão as empresas privadas que operam na comercialização de grãos - na condição de comerciantes diretos ou como prestadores de serviços de armazenagem.

\section{Considerações finais}

A armazenagem da produção agrícola é um ponto importante para a sustentabilidade do agronegócio brasileiro, mas a infraestrutura existente é insuficiente para guardar toda a produção de uma safra, o que força o escoamento direto, sem passar pelos pontos de armazenagem, ocasionando congestionamentos em rodovias e portos na época de safras. Para compreender melhor a evolução da armazenagem no Brasil, foi necessário entender como se prospectava a avaliação comparativa entre a evolução da produção de grãos e a da capacidade estática de armazenamento.

A análise demonstrou existir um grande potencial de expansão da demanda à espera por soluções em sistemas de armazenagem de grãos no Brasil e nos demais países produtores da América Latina e da África. Além da defasagem existente, a projeção de crescimento acelerado da demanda e da produção de grãos para os próximos anos desafiam os governos nacionais a desenvolverem políticas públicas 
de apoio e fomento aos investimentos de ampliação e qualificação da estrutura de armazenagem, comercialização e processamento de grãos. São essas as políticas públicas que tendem a estimular os investidores privados a contratar empresas fornecedoras de soluções para este setor.

A participação das lideranças representativas das empresas que compõem o APL Pós-Colheita na elaboração do Plano Nacional de Armazenagem no Brasil é de fundamental importância para concretizar ações de apoio e fomento que sejam viáveis e efetivas. Planos e políticas semelhantes devem ser estimulados em outros países com potencial de expansão da produção agrícola e também em âmbito estadual, especialmente nas regiões que apresentam maior carência e necessidade.

Apesar do grande desenvolvimento do agronegócio nacional, os problemas estruturais ainda persistem, impactando fortemente a sua expansão no Brasil, seja como atividade produtiva, seja como fonte de riqueza geradora de divisas internacionais de nosso país. Entre tais problemas, o mais importante em termos de impacto sobre o agronegócio nacional é a persistente ausência de infraestrutura adequada para o armazenamento e a comercialização da produção agropecuária, que levam a perdas consideráveis da produção.

De qualquer forma, fica clara a necessidade de investimentos ainda mais expressivos em infraestrutura de armazenagem no Brasil. Com melhores estruturas e uma melhor capacidade para armazenar a produção, pode ocorrer uma maior competitividade brasileira e um aumento da renda do produtor e demais agentes da cadeia produtiva. Os investimentos, todavia, também não podem ser feitos sem recursos disponíveis para a manutenção dos estoques, o que abre um novo ponto a ser melhorado pelos elaboradores dessas políticas de desenvolvimento de infraestrutura em determinada região, considerando as projeções futuras de aumento dessa produção agrícola.

Nesse sentido, o APL tem necessidade de desenvolver pesquisas e estudos buscando compreender a dinâmica de comportamento do mercado e os principais agentes com potencial de demanda pelos produtos e serviços oferecidos. Não basta contar com o crescimento da demanda global, que representa uma importante potencialidade, mas é preciso atentar para a competitividade das soluções oferecidas. Pelos estudos até aqui realizados, os segmentos com maior potencial de demanda são as empresas privadas (seguidas pelas cooperativas) ligadas ao processo de comercialização, especialmente as prestadoras de serviços de armazenagem, seguidas pelas que atuam no comércio de produtos agrícolas.

Para refletir sobre o problema colocado em questão, salienta-se que, para diminuir a defasagem logística no Estado, o financiamento de armazéns nas próprias fazendas é uma das alternativas viáveis, reduzindo a manipulação do produto, que passaria a ser transportado apenas uma vez para a indústria de beneficiamento, varejo e exportação. Como consequência, haverá menores perdas dos produtos, não ocorrendo escoamento desordenado para as regiões de comercialização e exportação. A alternativa seria investir nas unidades portuárias intermodais de transporte, que é o caso das unidades necessárias à transferência de cargas entre rodovias e ferrovias ou entre estas e as hidrovias ou portos marítimos. São unidades especializa- 
das, com requisitos de alto desempenho em movimentação de grãos (velocidade de carga e descarga). Dentro dessa expectativa, as empresas que compõem o APL PósColheita de Panambi e Condor teriam plenas condições de ampliar sua capacidade de armazenagem e ocupar uma fatia desse mercado.

\section{Referências}

BARROS, G. S. C. et al. Pesquisa de mercado e plano estratégico de fomento à agricultura e à estruturação nacional de armazenagem de grãos. Piracicaba: Centro de Estudos Avançados em Economia Aplicada; Cepea; ESALQ; USP, 2010.

BOWERSOX, D. J.; CLOSS, D. J. Logística Empresarial: O Processo de Integração da Cadeia de Suprimentos. São Paulo: Atlas, 2001.

BRASIL. Ministério do Desenvolvimento, Indústria e Comércio Exterior. Secretaria do Desenvolvimento da Produção. Departamento de Micro, Pequenas e Médias Empresas. Departamento de Competitividade e Tecnologia. Manual de Atuação em Arranjos Produtivos Locais, 2011.

- Coordenação-Geral de Arranjos Produtivos Permanente para Arranjos Produtivos Locais (GTP APL), 2008.

Local Metalmecânico Pós-Colheita, 2009.

Plano de Desenvolvimento - Arranjo Produtivo

CONAB. Companhia Nacional de Abastecimento. Acompanhamento da Safra Brasileira de Grãos. Disponível em: <http://www.conab.gov.br/OlalaCMS/uploads/ arquivos/12_10_17_16_09_58_boletim_graos_-julho_2012.pdf >. Acesso em: 1 nov. 2012

$\overline{\text { Brasília, }} \cdot \overline{2011 .}$

Acompanhamento de safra brasileira: grãos, terceiro levantamento.

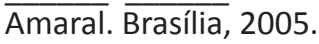

Armazenagem Agrícola no Brasil. Elaboração: Denise Deckers do

DECKERS, Denise. Situação de Armazenagem no Brasil. 2006. Brasília:

Conab, 2006.Disponível em: <http://www.conab.gov.br/OlalaCMS/uploads/ arquivos/713c763e53bbfc388225a7fcc52eb6ae..pdf>. Acesso em: 1 nov. 2012.

EMBRAPA. Empresa Brasileira de Pesquisa Agropecuária. Conferência aborda escoamento de safra. 2006. Disponível em: <http://www.embrapa. br/imprensa/noticias/2006/setembro/foldernoticia. 2006 06.0580910313/ noticia.27.0248142336/?searchterm=Conferência\%20aborda\%20escoamento\%20 de\%20safra>. Acesso em: 18 abr. 2015.

GIL, A. C. Técnicas de pesquisa em economia e elaboração de monografias. São Paulo: Atlas, 2000.

MARSHALL, A. Princípios de Economia. São Paulo: Abril Cultural, 1982. 
NOGUEIRA JUNIOR, Sebastião; TSUNECHIRO, Alfredo. Pontos críticos da

armazenagem de grãos no Brasil. Análises e Indicadores do Agronegócio, v. 6, n. 4, abr. 2011. Disponível em: <http://www.iea.sp.gov.br>. Acesso em: 13 out. 2012.

NORTH, Douglas C. A agricultura no crescimento econômico regional. Traduzido por Maria do Carmo Salazar Martins e revisado por Jacques Schwartzman de North, Douglass C. Agriculture in regional economic growth. Journal of Farm Economics, n. 41, v. 5, p. 943-951, dez. 1959. Com permissão do autor e de American Journal of Agricultural Economics.

PAIVA, C. Valor, preços e distribuição: de Ricardo a Marx, de Marx a nós. 1982. Tese. (Doutorado) - Universidade Estadual de Campinas, Campinas, 1998.

SMITH, Adam. A riqueza das nações. São Paulo: Abril Cultural, 1982. 